\title{
Análise da aplicabilidade da Matriz SWOT na gestão e planejamento em Ecoturismo: uma revisão da literatura
}

\section{Analysis of the applicability of the SWOT Matrix in Ecotourism management and planning: a literature review}

\author{
Ítalo de Paula Casemiro, Bruno Francisco Teixeira Simões, \\ Camila Maria dos Santos Moraes
}

\begin{abstract}
RESUMO: O presente artigo explora a ferramenta conhecida como Matriz SWOT, muito utilizada para diversos fins no processo de tomada de decisão, sendo empregada em diferentes contextos e áreas. Apesar de ser uma ferramenta muito comum na área de gestão de empresas, sua difusão fez com que adentrasse em diversos campos, tais como o turismo, que vem utilizando este recurso em diferentes processos de gestão e planejamento. Tendo em vista o uso da Matriz SWOT como ferramenta auxiliar no processo de gestão, o presente estudo por meio de uma revisão de escopo objetivou examinar como a Matriz SWOT tem sido utilizada na gestão e planejamento no ecoturismo, com a finalidade de sistematizar seus usos e aplicações, assim como as diferentes formas utilizadas para a sua elaboração. Os resultados indicam que, a referida ferramenta vem sendo utilizada com êxito para a gestão e planejamento de diferentes atividades turísticas com foco no ecoturismo, sendo que, seu uso atrelado a métodos quantitativos potencializa o resultado obtido. Além de fornecer recomendações sobre aspectos metodológicos e abordagens, a pesquisa apresenta os equívocos mais cometidos na utilização deste instrumento estratégico e suas diferentes possibilidades de uso, servindo como referência para gestores, planejadores e tomadores de decisão, no contexto do turismo sustentável, especialmente o ecoturismo.
\end{abstract}

PALAVRAS CHAVE: Análise Estratégica; Gestão Ambiental; Turismo Sustentável

ABSTRACT: This article explores the tool known as the SWOT Matrix, widely used for different purposes in the decision-making process, being used in different contexts and areas. Despite being a very common tool in the area of business management, its diffusion made it enter into several fields, such as tourism, which has been using this resource in different management and planning processes. In view of the use of the SWOT Matrix as an auxiliary tool in the management process, the present study, through a scope review, aimed to examine how the SWOT Matrix has been used in the management and planning of ecotourism, in order to systematize its uses and applications, as well as the different forms used for their elaboration. The results indicate that this tool has been successfully used for the management and planning of different tourist activities with a focus on ecotourism, and its use linked to quantitative methods enhances the result obtained. In addition to providing recommendations on methodological aspects and approaches, the research presents the most common mistakes made in the use of this strategic instrument and its different possibilities of use, serving as a reference for managers, planners and decision makers, in the context of sustainable tourism, especially ecotourism.

KEYWORDS: Strategic Analysis; Environmental Management; Sustainable Tourism. 


\section{Introdução}

No presente estudo, nos debruçamos sobre uma das ferramentas mais utilizadas no processo de gestão estratégica, a Matriz SWOT. Para Chermack e Kasshanna (2007), a Matriz SWOT ("strengths", "weaknesses", "opportunities" e "threats" ou numa tradução livre: pontos fortes, pontos fracos, oportunidades e ameaças) ajuda a identificar os problemas enfrentados em torno de uma determinada estratégia, seja para revisá-la ou para implementá-la. A SWOT é uma poderosa ferramenta, que pode ser aplicada a indivíduos, grupos, equipes, organizações ou planos/projetos (DAVID, 1997 apud CHERMACK; KASSHANNA, 2007). Diversos pesquisadores conhecidos na área da gestão estratégica, tais como Porter (1991) e Mintzberg (2009) defendem a Matriz SWOT como uma forma de realizar o alinhamento entre objetivos organizacionais, por meio da identificação de aspectos que interferem interna ou externamente sobre a organização. Desta forma e, pensando sobre o processo de tomada de decisão, o uso de ferramentas auxiliares com a Matriz SWOT, auxilia gestores a desenvolverem estratégias e ações mais fundamentadas.

Ao propor um olhar mais abrangente sobre a Matriz SWOT, nos desafiamos a apresentar o seu uso no contexto da gestão e planejamento no contexto do ecoturismo, abordando-a por meio de pesquisas que a utilizam, será possível melhorar a compreensão de como fazer uso desta ferramenta de forma eficaz. De modo geral, a presente pesquisa oferece aos profissionais e interessados no ecoturismo, aspectos introdutórios sobre o desenvolvimento da Matriz SWOT. Vale lembrar que, no contexto do turismo sustentável, especialmente o ecoturismo, os gestores são confrontados com diferentes desafios (MARANHÃO; AZEVEDO, 2019), neste sentido, o conhecimento sobre as ferramentas disponíveis para auxiliar no processo de gestão, podem ser fundamentais.

Apesar de ser muito utilizada, a Matriz SWOT é um instrumento de gestão que não possui diretrizes muito bem definidas para sua elaboração. Esse instrumento tem sido aplicado como auxiliar no processo de gestão e de tomada de decisão em diferentes áreas, inclusive no ecoturismo. Tendo em vista sua popularidade e a falta de uma orientação sobre o seu uso, este trabalho apresenta uma sistematização sobre o tema no ecoturismo, indicando usos, métodos e aplicabilidades.

A Matriz SWOT também conhecida nacionalmente como Matriz FOFA pode ser aplicada para diferentes fins de gestão e planejamento. Neste contexto, o presente estudo visa examinar como a SWOT tem sido utilizada na gestão e planejamento no âmbito do ecoturismo através de um mapeamento das evidências científicas existentes na literatura, respondendo a seguinte questão: Como a Matriz SWOT tem sido utilizada para auxiliar na gestão e planejamento no contexto do ecoturismo? Especificamente, pretende-se: 1) fornecer uma visão abrangente sobre a Matriz SWOT e seus usos na gestão e planejamento do ecoturismo; 2) descrever os principais equívocos no uso deste instrumento e; 3) apresentar os principais aspectos para a construção de uma Matriz SWOT, além claro, de apresentar o panorama dos estudos científicos que empregaram a Matriz. Os objetivos aqui propostos, permitem discutir como o uso deste instrumento tem sido feito na prática da gestão no ecoturismo, de modo a indicar diretrizes, oportunidades de pesquisa e sistematizar o seu uso. 


\section{Referencial Teórico}

\section{Planejamento em Ecoturismo}

O ecoturismo representa um conceito ambiental e econômico do turismo, e viabilizado por atividades turísticas de baixo impacto, participação local no processo de planejamento e ações de preservação e proteção das diversidades locais, sejam elas naturais, culturais ou históricas (DEMIR; ATANUR, 2019). Tal vertente do turismo é vista como um tipo de turismo alternativo ao turismo de massa, isto é, a um turismo globalizado, que atrai grandes contingentes de turistas (URRY, 1996) e que tem por base a sustentabilidade (IBRET; AYDINOZU; BASTEMUR, 2013; IYE 2018).

Como o paradigma da sustentabilidade tornou-se uma máxima a ser alcançada em qualquer atividade, este também se tornou uma estrutura importante no turismo, sendo que o ecoturismo é visto com um elemento-chave na busca por um turismo sustentável (ZORLU; YILMAZ, 2020). E, dentre as vertentes do turismo, o ecoturismo é aquele que melhor dialoga com objetivos sustentáveis, como a conservação da biodiversidade, proteção ambiental, valorização das culturas tradicionais locais e melhoria econômica (COSTA; GOMES, 2014; ANUP, 2016 apud ASADPOURIAN; RAHIMIAN; GHOLAMREZAI, 2020) e, isso se reflete no seu crescimento ao longo dos últimos anos (AKBULAK; CENGIZ, 2014).

O ecoturismo tem como princípios gerais:

minimizar o impacto, usar a educação ambiental para conscientizar, construir respeito ambiental e cultural, usar operações e gerenciamento sustentáveis, fomentar experiências positivas tanto para visitantes como para anfitriões, possibilitar apoio direto e benefícios financeiros para a conservação da natureza e propiciar benefícios econômicos e capacitação para a população local (RANGEL; SINAY, 2019, p. 565).

De modo geral, o ecoturismo está orientado para gerar visitas em espaços naturais e de forma responsável, fomentando a conservação e a melhoria das condições de vida da população local (LÓPEZ SANTILLÁN; GUARDADO, 2012; VARGAS DEL RÍO; BRENNER, 2013). Desta forma, alguns fatores são importantes para o desenvolvimento deste tipo de turismo, tais como: a inserção produtiva de comunidades locais; educação ambiental; conservação de recursos naturais e menor degradação ambiental; conservação de espécies e do patrimônio cultural envolvidos (ASADPOURIAN; RAHIMIAN; GHOLAMREZAI, 2020).

As áreas protegidas são áreas potenciais para o desenvolvimento do ecoturismo, por conta de sua biodiversidade, características paisagísticas excepcionais, recursos naturais e patrimônio cultural das comunidades locais (AÇIKSÖZ et al., 2016). Contudo, para explorar tais riquezas, a atividade do ecoturismo deve levar em consideração um planejamento adequado para o local, que contribuirá para a diminuição dos impactos ambientais causados especialmente na fauna e flora (SPAOLONSE; MARTINS, 2016).

São diversos os recursos naturais que podem ser explorados pelo ecoturismo, tais como montanhas, cavernas, praias, florestas, ruínas, entre tantos outros recursos naturais, além dos recursos culturais como artesanato, alimentos, 
eventos, entre outros. Embora nem todos os recursos citados anteriormente estejam presentes em determinadas áreas onde o ecoturismo é desenvolvido, é fundamental determinar os recursos presentes e desenvolver sua gestão de forma sustentável (OKAN et al., 2016).

Assim para viabilizar a atividade turística de forma sustentável, uma série de variáveis podem subsidiar o planejamento, gestão, monitoramento e avaliação dos impactos desta atividade no desenvolvimento das regiões turísticas (BRASIL, 2007). Como notam Cohen e Silva (2010), muitas vezes, os atores envolvidos no processo de planejamento do ecoturismo, carecem de uma visão estratégica, no sentido de considerar o ecoturismo como uma poderosa forma de incentivar o desenvolvimento local sustentável. No Quadro 1 são apresentadas algumas das variáveis mais comuns no planejamento do turismo sustentável e suas definições.

Quadro 1: Variáveis Utilizadas no Planejamento Turístico Sustentável

Frame 1: Variables Used in Sustainable Tourism Planning.

\begin{tabular}{|c|c|}
\hline Variável & Descrição \\
\hline $\begin{array}{l}\text { Sustentabilidade } \\
\text { ambiental }\end{array}$ & $\begin{array}{l}\text { A maneira de assegurar a compatibilidade do desenvolvimento com a } \\
\text { manutenção dos processos ecológicos essenciais, bem como da diversidade } \\
\text { dos recursos. (p.28). }\end{array}$ \\
\hline $\begin{array}{l}\text { Sustentabilidade } \\
\text { econômica }\end{array}$ & $\begin{array}{l}\text { É entendida como a garantia de um crescimento turístico eficiente: a } \\
\text { conciliação entre a criação de postos de trabalho, com níveis satisfatórios de } \\
\text { renda, e o controle sobre os custos e benefícios dos recursos, que garante a } \\
\text { continuidade para as gerações futuras". (p.32). }\end{array}$ \\
\hline $\begin{array}{l}\text { Sustentabilidade } \\
\text { sociocultural }\end{array}$ & $\begin{array}{l}\text { É um processo que visa à melhoria da qualidade de vida e redução dos níveis } \\
\text { de exclusão social, por meio de uma distribuição mais justa da renda e dos } \\
\text { bens. (p.35). }\end{array}$ \\
\hline $\begin{array}{l}\text { Sustentabilidade } \\
\text { "político- } \\
\text { institucional" }\end{array}$ & $\begin{array}{l}\text { Refere-se à solidez e continuidade das parcerias e dos compromissos } \\
\text { estabelecidos entre os diversos agentes e agências governamentais dos três } \\
\text { níveis de governo e nas três esferas de poder, além daqueles atores situados } \\
\text { no âmbito da sociedade civil. (p.41). }\end{array}$ \\
\hline
\end{tabular}

Fonte: Brasil (2007).

Source: Brazil (2007).

Como notado no Quadro 1, por mais que estas variáveis da sustentabilidade no turismo estejam separadas, não há como se pensar em sustentabilidade sem que exista uma integração entre todas estas. Estas funcionam como diretrizes gerais, que são basilares para o desenvolvimento de um planejamento do turismo numa perspectiva sustentável, tendo em vista, tanto os impactos negativos, quanto positivos decorrentes da prática do turismo. Neste sentido, a próxima seção se dedica a apresentar os usos da Matriz SWOT nos estudos do turismo.

\section{A Matriz SWOT para Análise do Turismo}

A Matriz SWOT apresenta um papel relevante na formulação de estratégias de desenvolvimento turístico de destinos, uma vez que, ajuda a estabelecer um diagnóstico confiável do potencial demostrado por um destino turístico e seu ambiente (GORANCZEWSKI; PUCIATO, 2010).

O turismo tem ganhado grande importância econômica, principalmente em economias regionais de vários destinos, o que justifica uma política de turismo bem gerida como prioridade. Estratégias regionais para o desenvolvimento do turismo, 
devem basear-se em análises confiáveis dos potenciais internos e externos do ambiente, e a Matriz SWOT possibilita isto (GORANCZEWSKI; PUCIATO, 2010).

No contexto do turismo, a SWOT é amplamente utilizada, o que é perceptível pelo número de investigações que utilizam esta ferramenta tanto no contexto nacional como no contexto internacional para os mais diversos fins de planejamento e gestão de atrativos, destinos turísticos etc. (ver: MORALESFERNÁNDEZ; LANQUAR, 2014; AVILA et al., 2015; GARCÍA REINOSO; CHILAN; YAMIL, 2017; ARÉVALO et al., 2018; GARCÍA; QUINTERO, 2018; PFEIFF et al., 2018). Cabe destacar o uso da ferramenta, tanto em nível micro quanto macro, como pode ser notado por diversos estudos.

Vladi (2014) desenvolveu uma análise do estágio do turismo na Albânia por meio do uso da Matriz SWOT, onde identificou diversos aspectos que limitam a atratividade turística deste país (por exemplo, a falta de estratégias para que os turistas possam ser promotores de uma imagem positiva da Albânia), assim como outros que poderiam ser explorados para aumentar o turismo na região (tais como a variedade de produtos turísticos presentes no território).

Como forma de auxiliar no processo de planejamento estratégico direcionado a um modelo de desenvolvimento de turismo sustentável, Sulistyad, Eddyono e Hasibuan (2017) também utilizaram a Matriz SWOT para estudar o caso de Thousand Islands, área turística de Jacarta na Indonésia, onde conseguiram desenvolver uma série de estratégias, que envolveram desde o reforço do compromisso entre as partes interessadas, o protagonismo das comunidades locais e o reforço dos princípios do turismo sustentável. Outro estudo que utilizou a Matriz SWOT para diagnosticar a sustentabilidade turística, foi o de Mondal (2017) que identificou que as atividades atuais de turismo em Bangladesh não estão adequadas a uma perspectiva sustentável do turismo.

Num estudo sobre a Lalibela, um patrimônio cultural da Etiópia, Nega (2018) aplicou a Matriz SWOT obtendo dados através de entrevistas, documentos e observações, identificando que, o referido patrimônio possui como principais fraquezas, a falta de profissionais, problemas orçamentários e falta de preocupação por parte da UNESCO; enquanto, entre os pontos fortes estão: festivais únicos, estabelecimentos de qualidade, cultura indígena, 11 igrejas talhadas em rocha e topografia espetacular. Como destaca o autor, a partir dos achados, as partes interessadas do destino de Lalibela devem tentar identificar e minimizar as fraquezas e usar os pontos fortes e as oportunidades para garantir o desenvolvimento sustentável do turismo neste destino.

Mustika e Aditya (2018), investigaram a situação da uma vila turística, apresentando estratégias e diretrizes para desenvolver o turismo em Kampung Tajur, Pesanggrahan Village e Purwakarta (Indonésia) usando a Matriz SWOT e identificaram que, nas áreas pesquisadas observa-se que o limiar de vulnerabilidade para as áreas rurais pode ser extremamente alta devido à abertura aos turistas, tal situação requer revisão e apresentação de políticas apropriadas para aumentar pontos fortes, minimizar os pontos fracos e ameaças, assim como explorar as oportunidades locais.

Analisando pesquisas que aplicam a Matriz SWOT em destinos turísticos, é notória a importância da ferramenta para auxiliar a gestão em diferentes escalas (país, cidade, atrativo, etc.), assim como envolver as partes interessadas no desenvolvimento de planejamentos estratégicos com vistas a promover a atividade 
turística e de forma sustentável, por meio da identificação dos pontos fortes, fracos, oportunidades e ameaças à prática da atividade turística, além claro, de subsidiar o desenvolvimento de estratégias.

O desenvolvimento do turismo de forma sustentável apresenta muitos desafios e, enfrentar tais desafios é tarefa importante para os formuladores de políticas e para as comunidades envolvidas com a atividade turística, sendo que, a Matriz SWOT se apresenta como um instrumento com grande potencial para auxiliar no processo de gestão, planejamento e tomada de decisão.

\section{Metodologia}

A presente pesquisa foi elaborada com o objetivo de examinar o status do uso da Matriz SWOT na área do ecoturismo. Para isso, foi adotada uma revisão do tipo escopo seguindo a estrutura proposta por Arksey e O'Malley's (2005) descrita a seguir: (1) identificar a questão de pesquisa, (2) identificar estudos relevantes, (3) seleção de estudos, (4) mapear os dados e (5) agrupar, resumir e relatar os resultados.

Para os fins desta investigação, a revisão de escopo é tida como um tipo de revisão da literatura, onde almeja-se mapear a literatura sobre um tópico específico, buscando oferecer a oportunidade de se identificar conceitos, lacunas de pesquisa e fontes de evidências (DAUDT et al., 2013). Deste modo, a análise é efetuada por meio de uma abordagem qualitativa e descritiva (LEVAC; COLQUHOUN; O'BRIEN, 2010).

\section{Coleta de Dados}

A coleta de artigos foi realizada no dia 24 de setembro de 2020 em dois repositórios de estudos científicos, a saber: Web of Science e Scopus. Estas bases foram selecionadas por serem amplamente conhecidas, por sua abrangência e diversidade de pesquisas, por conta da qualidade dos estudos, tendo em vista que os melhores periódicos de diferentes campos científicos encontram indexados nestas e por abrangerem uma gama variada de disciplinas.

Para a coleta de estudos, não foram limitadas questões relacionadas a data, ou seja, não foi definida uma faixa temporal, mas foram coletados estudos publicados até o ano de 2020 e foram aceitos estudos em quaisquer idiomas. A consulta consistiu em termos considerados pelos autores como descritores para recuperar estudos sobre a temática da Matriz SWOT no contexto do ecoturismo. Assim, uma busca generalista foi feita utilizando a seguinte estratégia de busca em ambas as bases, juntamente com os operadores booleanos AND e OR: (SWOT OR "SWOT Analysis") AND Ecotourism. Esta proposta de busca teve como diretriz restringir a busca por estudos que relacionavam o uso da Matriz SWOT com o ecoturismo. A consulta foi adaptada aos requisitos de cada banco de dados, assim, na base Scopus foram pesquisados os filtros título, resumo e palavras-chave, enquanto, na base Web of Science foi utilizado o filtro "tópico". É importante destacar que, há uma vasta literatura sobre o uso da Matriz SWOT na perspectiva do turismo sustentável, que não foi considerada para este estudo. 
Para a seleção de estudos, foi desenvolvida a leitura dos títulos e resumos dos artigos científicos, assim como a verificação do atendimento aos critérios de exclusão e inclusão estabelecidos, conforme apresentado no Quadro 2.

Quadro 2: Critérios de Inclusão e Exclusão.

Frame 2: Inclusion and Exclusion Criteria.

\begin{tabular}{|l|}
\multicolumn{1}{|c|}{ Critérios de Inclusão } \\
\hline Artigos revisados por pares; \\
Artigos empíricos, isto é, artigos onde a Matriz \\
SWOT foi desenvolvida; \\
Estudos publicados em inglês, português ou \\
espanhol; \\
Estudos que tratavam de objetos relacionados \\
com o ecoturismo.
\end{tabular}

\section{Critérios de Exclusão}

Publicações diferente de artigos, tais como resumos, editoriais, teses, dissertações, relatórios, resenhas, comentários, entre outros;

Artigos que apenas referenciam a Matriz SWOT ou artigos apenas teóricos, sem descrever o processo de elaboração da ferramenta.

Fonte: Elaborado pelo autor (2020).

Source: Prepared by the author (2020).

Depois de comparar os resultados dessas buscas, foram retirados os estudos duplicados, restando 54 artigos que atenderam ao objetivo da pesquisa. Como forma de aumentar o rigor metodológico, assim como a transparência, seguimos o modelo PRISMA para o check-list dos passos utilizados na pesquisa (TRICCO et al., 2018). Na Figura 1 é apresentada a sistematização do processo de coleta dos artigos selecionados.

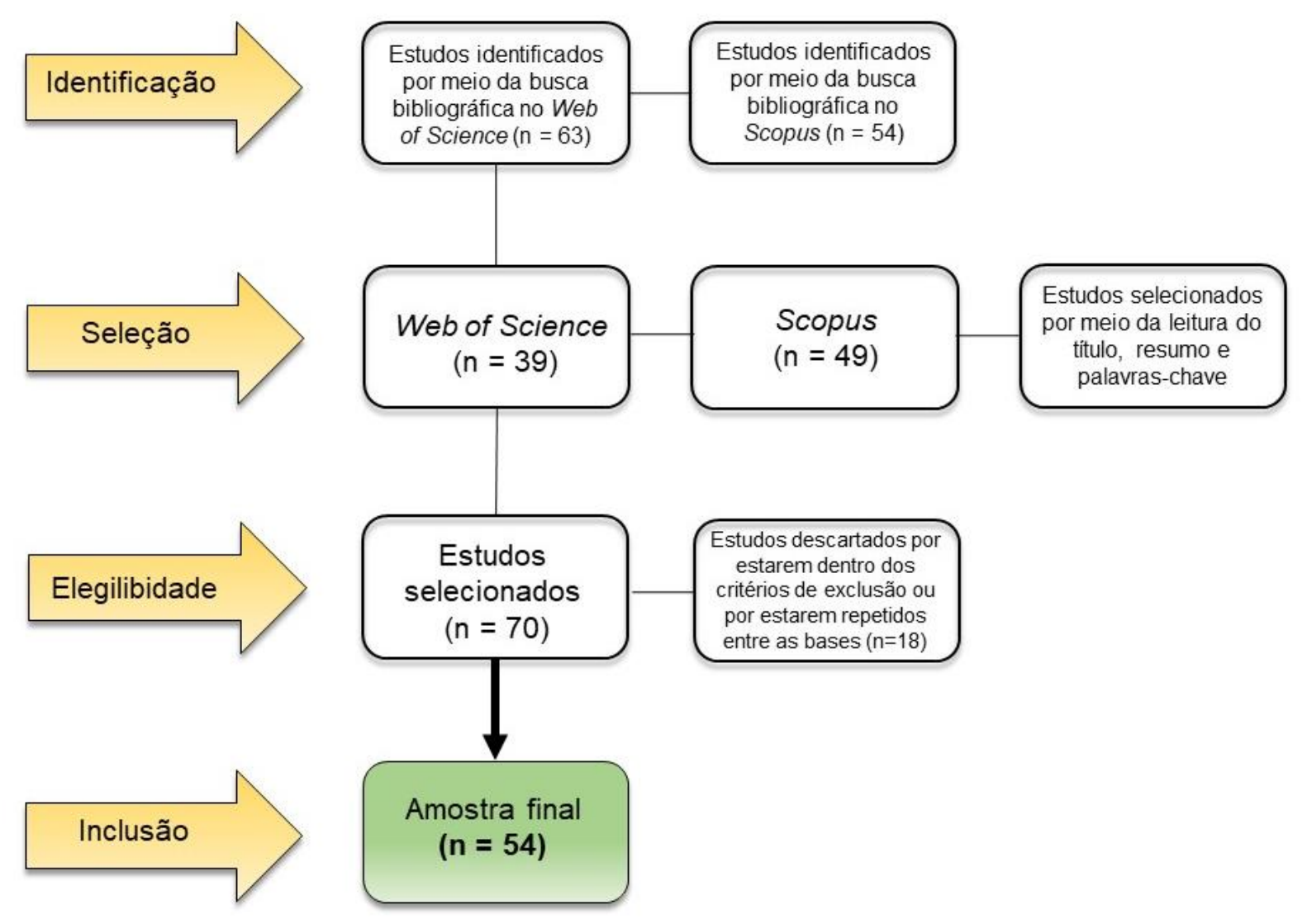

Figura 1: Sistematização do Procedimento de Coleta de Estudos.

Figure 1: Systematization of the Study Collection Procedure.

Fonte: Elaborado pelo autor (2020).

Source: Prepared by the author (2020). 


\section{Análise dos Dados}

Os dados foram extraídos por meio de um formulário específico desenvolvido pelos autores no software Microsoft Excel (2013), seguindo as recomendações de Peters et al. (2015), no intuito de caracterizar informações como ano da publicação, periódico, país onde foi desenvolvido o estudo, objeto de estudo, fonte de dados, instrumentos de coleta e meios utilizados para desenvolver a Matriz SWOT, entre outras informações, como os principais achados dos estudos. Análises por meio de estatísticas descritivas foram feitas para resumir os dados.

\section{Resultados e Discussão}

\section{Matriz SWOT : Uma Ferramenta Qualitativa e Multifuncional}

A Matriz SWOT tem sido utilizada em diferentes países para a gestão do ecoturismo, mas analisando a distribuição por continente, pode-se notar uma grande disparidade no uso, com destaque para o continente asiático, onde esta ferramenta, aparentemente, tem sido utilizada com maior frequência para o planejamento em ecoturismo. Neste ponto, chama a atenção o número de estudos que foram desenvolvidos na Turquia $(n=14)$. Cabe ressaltar que, a Turquia é um país que se divide entre dois continentes (Europa e Ásia), sendo que neste estudo optamos por enquadrá-la na Ásia, por ser um país que não faz parte da União Europeia, além de ter a maior parte de seu território no continente asiático. O mesmo critério foi utilizado para a Rússia, sendo esta considerada pertencente à Ásia. Na Figura 2, é possível observar a distribuição dos estudos por continente.

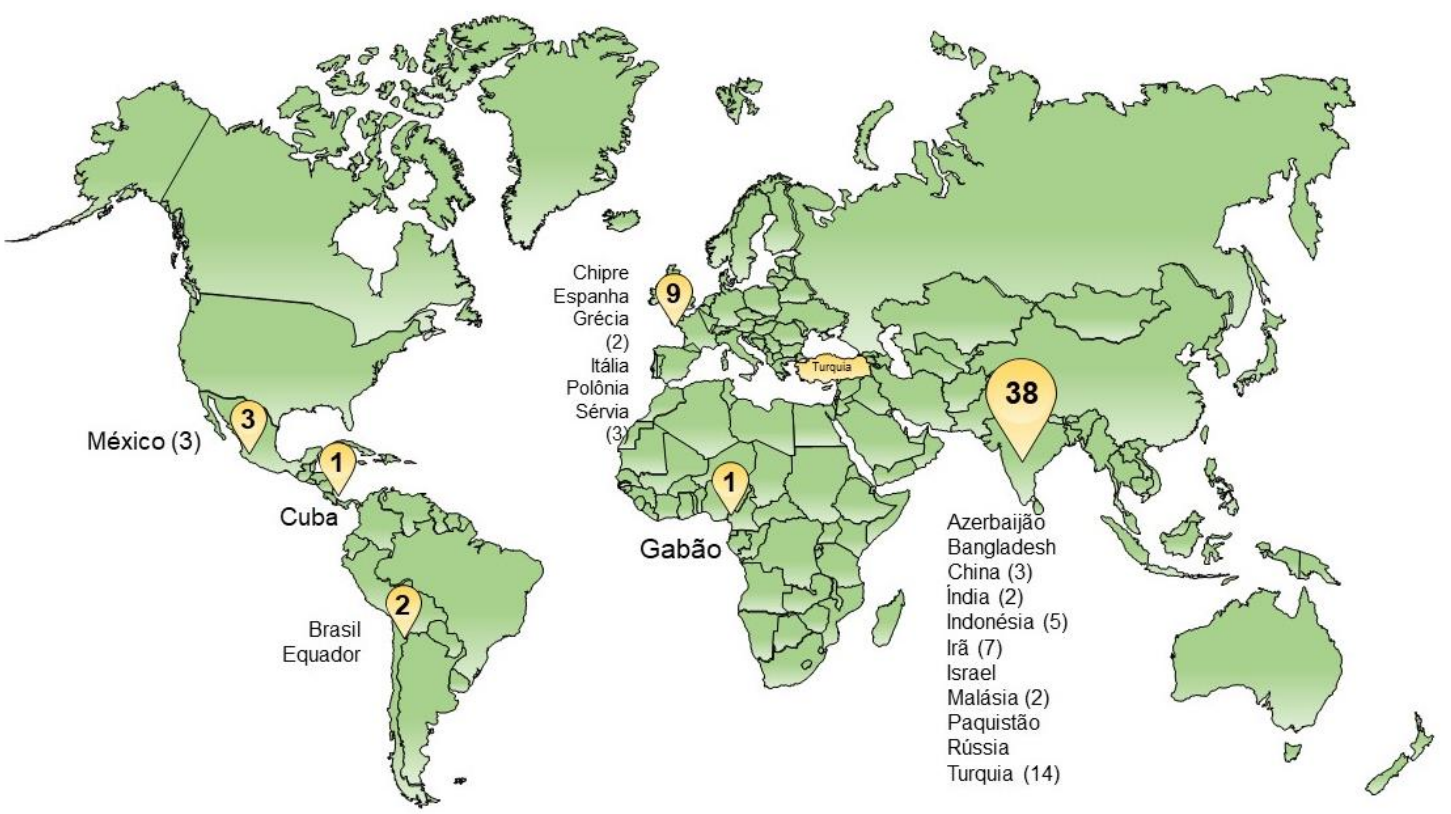

Figura 2: Distribuição dos Estudos Utilizando a Matriz SWOT por país/continente.

Figure 2: Distribution of Studies Using the SWOT Matrix by country/continent.

Fonte: Dados da Pesquisa (2020).

Source: Research Data (2020).

Nota-se pela Figura 2, que não há estudos desenvolvidos em países da Oceania e, existe apenas um estudo utilizando a SWOT no continente africano sendo poucos os trabalhos desenvolvidos em países das Américas $(n=06)$. Mas, deve-se considerar que o presente estudo se limitou a analisar duas bases de dados 
científicos, desta forma, não é possível generalizar os achados da pesquisa, pois pode haver estudos que estejam acessíveis apenas em outras bases.

Algo que também se destaca entre os resultados é o uso ainda novo da ferramenta, sendo que a maior parte dos estudos são posteriores ao ano de 2010 (n = 53), o que demonstra um uso recente na área, apesar de a ferramenta datar dos anos 70. Como pode ser notado no Gráfico 1, tem havido um crescimento do uso da ferramenta a partir de 2010.

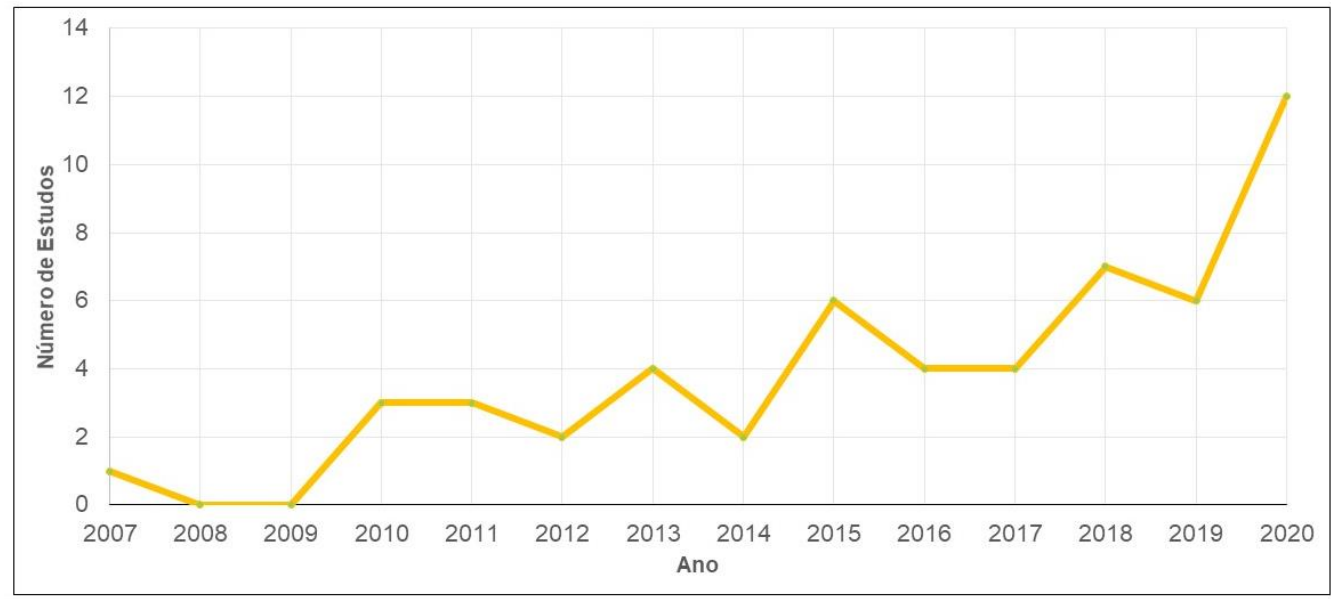

Gráfico 1: Demonstração da Distribuição Anual dos Estudos

Graph 1: Demonstration of the Annual Distribution of Studies

Fonte: Dados da Pesquisa (2020).

Source: Research Data (2020).

Quanto aos periódicos onde os estudos foram publicados, é possível notar uma grande variedade $(n=43)$, mas com destaque para o International Journal of Sustainable Development \& World Ecology, com sete estudos utilizando a Matriz SWOT dentro da amostra final.

Os estudos revelam uma diversidade de usos da Matriz SWOT dentro do contexto do ecoturismo com objetos distintos, seja para o planejamento de atividades como a observação de pássaros (KRONENBERG, 2016), observação de tubarões (MEZA-ARCE et al., 2020) avaliação e planejamento da prática do ecoturismo em áreas protegidas (APs) (RANDLE; HOYE, 2016; LY; XIAO, 2016; KANGAS et al., 2016, ARSIĆ et al., 2018). Também é possível notar o uso em diferentes escalas, tanto a nível local, como estudos aplicados a cidades (PIRSELIMOĞLU; DEMIREL, 2012; LESTARI et al., 2019) e chegando a análises mais amplas, envolvendo países (MOSTAFAVI; JOZ, 2015). O uso da Matriz na gestão do ecoturismo, conforme observado pelos resultados é predominantemente utilizada para a gestão e planejamento de atividades de observação da natureza, planejamento do ecoturismo em biomas/territórios e, comumente para áreas de conservação da natureza, tais como parques.

Um estudo que utilizou a Matriz SWOT para avaliar o potencial para o desenvolvimento do ecoturismo, foi o estudo de Ching et al. (2020). Nele, os autores identificaram que o Planalto de Cameron na Malásia possui muitas oportunidades para desenvolver um turismo sustentável por meio do ecoturismo, tendo potencial para se tornar um grande ponto de ecoturismo na região, mas na análise empreendida pelos autores, foi possível notar que, atualmente as atividades não estão adequadas ao emprego do ecoturismo e suas práticas. Como afirma Mugo et al. (2017) ao desenvolver uma Matriz SWOT é possível ter uma compreensão 
holística de diferentes fatores que podem afetar positiva ou negativamente a tomada de decisão e o planejamento estratégico.

A Matriz SWOT também pode ser utilizada para analisar atividades específicas, tais como a observação de pássaros. Kronenberg (2016), utilizou a ferramenta para analisar o potencial e o desenvolvimento da observação de pássaros na Polônia, onde identificaram uma abundância de espécies de pássaros e ecossistemas naturais intactos (pontos fortes) e infraestrutura turística subdesenvolvida e insuficiente informações sobre espaços poloneses de observação de pássaros (pontos fracos). A observação de pássaros, inclusive, é um dos segmentos do ecoturismo que teve maior crescimento nos últimos anos (CREST, 2015 apud KRONENBERG, 2016), sendo justificado o uso da Matriz SWOT para o seu planejamento estratégico, tendo em vista a exploração do potencial desta atividade.

Outro uso da Matriz SWOT no contexto do ecoturismo, é na formulação de indicadores para avaliação do desenvolvimento do turismo sustentável. Como proposto por alguns estudos (VAGIONA et al., 2017; ASADPOURIAN; RAHIMIAN; GHOLAMREZAI, 2020), a Matriz pode ser um meio para se estabelecer indicadores, que refletem os pilares do desenvolvimento sustentável. Além disso, como alguns estudos demonstram (AKBULAK; CENGIZ, 2014; ANGGORO et al., 2019; ZORLU; YILMAZ; 2020), a Matriz SWOT pode ser utilizada, inclusive, para determinar a viabilidade de implantação do ecoturismo em determinados destinos, na perspectiva da gestão sustentável da atividade turística.

Reihanian et al. (2012) analisando a estratégia para o desenvolvimento do turismo sustentável por meio da Matriz SWOT no Parque Nacional Boujagh, no Irã, notaram que as atividades existentes neste parque não atendiam os requisitos da sustentabilidade. Não por acaso, o instrumento é uma ótima forma de determinar, por exemplo, que atividades ecoturísticas são mais adequadas para cada Unidade de Conservação, como feito no estudo de Celik (2018), no Parque Natural Balamba Turquia, onde os autores, por meio de uma Matriz SWOT identificaram o turismo botânico, trekking, safáris fotográficos, safáris de bicicleta e observação de pássaros/borboletas como atividades mais adequadas a este parque, ou seja, a Matriz é de extrema utilidade para se determinar prioridades dentro de um processo de planejamento e gestão de atividades recreativas em parques. A Matriz SWOT, para além do seu uso no planejamento, também é uma forma de desenvolver um diagnóstico sobre determinada realidade, apreendendo os fatores que the afetam internamente e externamente.

Analisando por meio de uma Matriz SWOT o Parque Nacional de Caguanes em Cuba, Navarro-Martínez et al. (2020) identificaram entre os pontos fortes do parque a diversidade de ecossistemas marinhos e terrestre e a diversidade de espécies importantes para a conservação; já entre os pontos fracos, foi notado a insuficiência no manejo de espécies invasoras, as falhas no sistema de trilhas (extensão, acessibilidade...), a deficiência na infraestrutura do parque e falta de especialistas e pessoal de apoio. Cabe destacar que, a SWOT também tem sido um instrumento importante para determinar a eficácia das estratégias de conservação em áreas protegidas (SCOLOZZl et al., 2014).

A Matriz possibilita identificar fatores internos a determinado objeto, tais como recursos, capacidades etc. e classificá-los em pontos fortes ou fracos. Paralelamente, permite analisar e classificar fatores externos, tais como localização geográfica, disponibilidade de mercado e classificá-los como oportunidades ou 
ameaças (MEZA-ARCE et al., 2020). Tal fim, permite o uso desta ferramenta para explorar estratégias possíveis de modo a desenvolver e consolidar forças ou superar fraquezas, ou seja, é um instrumento importante para enfrentar a mudança de ambiente dentro de uma perspectiva de planejamento estratégico e processos de tomada de decisão. Como defendido no estudo de Meza-Arce et al. (2020), o uso da Matriz SWOT permite que os atores envolvidos tenham uma visão geral sobre os aspectos fortes e fracos a serem considerados para melhorar sua gestão.

Como o planejamento e a ação em relação ao desenvolvimento do ecoturismo, pensando numa perspectiva sustentável, deve contemplar aspectos ambientais, sociais e econômicos, é necessário identificar e avaliar as áreas prioritárias para o desenvolvimento sustentável do ecoturismo, sendo assim, os estudos demonstram que a Matriz SWOT pode ser uma excelente ferramenta neste sentido. Algo relevante de ser pensado dentro do processo de planejamento estratégico de um determinado atrativo turístico utilizando a Matriz SWOT é a declaração da visão específica deste, isto é, o que se almeja com o planejamento, por exemplo, tornar determinada região um polo de ecoturismo etc. Ou seja, estabelecer o que se pretende com o uso da ferramenta, deve ser um objetivo inicial fundamental para justificar o uso da ferramenta.

Num segundo momento, como destacado em alguns estudos (MESTANZARAMÓN et al., 2020; MALLICK; RUDRA; SAMANTA, 2020), o estabelecimento de questões norteadoras para a identificação dos elementos que vão compor a Matriz, também pode ser algo que contribua no processo. Isto é particularmente relevante, pois delimitar de forma clara, as questões que vão nortear a definição dos aspectos a serem desenvolvidos, é um passo inicial importante para o desenvolvimento da ferramenta. Ter a clara dimensão de que as questões captam aspectos internos e externos, ajudam a direcionar a identificação dos aspectos de forma mais precisa. No estudo de Mallick, Rudra e Samanta (2020, p.188), por exemplo, os autores usaram questões tais como "O que leva os turistas a escolher este tipo de local?" e "Quais são os serviços disponíveis especialmente para os turistas?" para determinar os pontos fontes de Rameswaram no estado indiano de Tamil Nadu na perspectiva do desenvolvimento turística da região.

Ao desenvolver a Matriz SWOT, é importante estabelecer os limites da análise e, a identificação adequada dos aspectos que são inerentes ao ambiente interno e externo. Elencar questões é uma etapa preliminar do desenvolvimento da Matriz SWOT para a determinação dos elementos que vão compor cada quadrante para realizar uma Matriz SWOT, perguntas devem ser feitas para direcionar a identificação dos elementos que irão compô-la (COLLINS-KREINER; WALL, 2007). Além disso, ao analisar os aspectos que compõem a Matriz SWOT é relevante ponderar sobre o conteúdo de cada quadrante, isto é importante, pois por mais que se reconheça um aspecto como ponto forte, eles podem conter uma ameaça oculta, por exemplo (CHERMACK; KASSHANNA, 2007).

Após a definição dos objetivos e questões iniciais, cabe estabelecer as fontes de obtenção de dados e os instrumentos utilizados para a coleta destes. De modo geral, os estudos se utilizam de diversas fontes de informação para construir a Matriz SWOT, a saber: bibliografia (artigos, documentos oficiais, relatórios, leis, brochuras turísticas, estudos, entre outros); experts (neste grupo, há uma variedade de públicos, tais como acadêmicos, profissionais com anos de experiência na área), autoridades públicas, guias turísticos, habitantes locais, turistas, gestores envolvidos 
com o turismo, alunos de pós-graduação, representantes de organizações não governamentais, representantes de organizações estatais, empresários e ativistas.

A figura dos experts é muito presente no processo de construção da Matriz SWOT. Isso se justifica, por conta de a necessidade desta ferramenta ser desenvolvida com base num determinado contexto e por pessoas, que além de compreendê-lo possam contribuir pensando sobre os diferentes temas e aspectos que estão inseridos no ambiente analisado. Por isso, justifica-se a inclusão de pesquisadores e gestores, como representantes da categoria experts. Como a Matriz SWOT é conduzida por meio de uma base qualitativa, seu uso depende do conhecimento e habilidades de competência no processo de planejamento (KAJANUS et al., 2012).

A participação de equipes multidisciplinares, de diferentes áreas científicas e instituições na elaboração de ferramentas como a matriz SWOT fortalece o processo ao considerar diferentes aspectos do conhecimento científico, tradicional e da gestão ambiental (NAVARRO-MARTíNEZ et al., 2020). Ao selecionar os tomadores de decisão, o conhecimento destes a experiência e o comprometimento com o local, são elementos mais importantes que o tamanho da amostra, segundo Saaty e Özdemir (2015).

Algo que colabora no desenvolvimento da Matriz SWOT é a participação de diferentes partes interessadas (stakeholders) no processo de identificação dos elementos que irão compô-la. Essa participação é importante, pois com a participação de diversos agentes, é possível não só obter uma visão mais holística sobre o objeto analisado, com também envolver todos os interessados de forma participativa no processo de gestão.

Metodologicamente, muitos estudos dentro da amostra analisada $(n=54)$ não deixam claro os métodos de coleta e tratamento de dados, além da fonte dos dados, o que inclusive limitou parte das análises destes estudos. Vejamos o exemplo do uso de grupos focais. Alguns estudos citam o método (por exemplo: AÇIKSÖZ et al., 2016; ANGGORO et al., 2019), mas não descrevem o número de participantes, o roteiro que conduziu a dinâmica do grupo, entre outros aspectos que deixam dúvidas sobre os modos como a técnica foi conduzida. O mesmo fato é observado em estudos (por exemplo: PIRSELIMOĞLU; DEMIREL, 2012; ARINTOKO et al., 2020) que utilizam a técnica da entrevista, pois muitos deles, não especificam o tipo de entrevista e como foram feitas. Esses são alguns aspectos que fragilizam os estudos identificados nesta pesquisa.

Dentre os principais recursos utilizados para o desenvolvimento da Matriz SWOT, destacam-se: entrevistas, questionários, observações de campo, grupos focais, workshop, pesquisa documental (fotos, vídeos, gravações, sites, documentos oficiais). Destacam-se neste universo o uso de entrevistas $(n=20)$ e questionários $(n=20)$. Contudo, nota-se que, o workshop parece ser um instrumento mais adequado ao desenvolvimento de uma Matriz SWOT no que se refere ao nível de participação dos atores envolvidos, tendo em vista que por meio deste instrumento, a ferramenta pode ser desenvolvida de uma forma mais interativa e colaborativa, podendo envolver um conjunto diverso de atividades e um engajamento maior entre os participantes, como demonstrado no estudo de Kurttila et al. (2020). É claro que, muitos estudos utilizam estes e outros instrumentos de forma combinada, o que é uma forma de obter diferentes informações, oriundas de diferentes fontes.

Algo que se nota em diversos estudos da amostra, é a indicação da obtenção de dados por meio de documentos, tais como relatórios, documentos 
institucionais, entre outros. Contudo, alguns estudos não deixam claro que documentos foram utilizados. Isso também ocorre, quando os autores indicam a pesquisa bibliográfica como fonte dos dados. Ao indicar a busca bibliográfica ou revisão da literatura, o direcionamento fica muito abrangente, não sendo possível identificar quais tipos de bibliografias foram utilizadas.

Não há na literatura a indicação sobre a quantidade de fatores que devem ser apontados nos quadrantes da Matriz SWOT. Mas, de um modo geral, o que se nota nos estudos é uma variação no número de aspectos elencados em cada quadrante. É importante notar que, o estabelecimento de muitos fatores dentro da Matriz SWOT pode tornar a execução de planos mais complexa ou até inviabilizar estes, tendo em vista a variedade de estratégias e ações que poderão surgir a partir da Matriz. De modo geral, observa-se entre 10 e 20 itens indicados por quadrante.

A Matriz SWOT pode ser representada de diferentes formas. Dentro do escopo dos estudos analisados, observa o uso recorrente do formato de Tabela/Quadro $(n=46)$, como meio para apresentar os aspectos que compõem a Matriz. Também foi possível notar o uso de Gráficos $(n=2)$ e a apresentação dos aspectos de forma descritiva no corpo do texto do artigo $(n=6)$.

De modo geral, há na literatura estudos utilizando a Matriz SWOT de forma isolada para o desenvolvimento de estratégias, enquanto há outro eixo de estudos utilizando esta ferramenta, associada a outros recursos, como a matriz TOWS, lógica fuzzy, métodos quantitativos para priorização dos fatores obtidos na Matriz SWOT. Cabe ressaltar que, apesar de existir um modelo tradicional de uso da Matriz, por meio de quadrantes, já existem modelos híbridos, onde adiciona-se outros recursos a ferramenta, especialmente recursos quantitativos para aprimorar a ferramenta e análise de estratégias, onde se identifica as relações entre esses fatores e seleciona as estratégias com base no relacionamento entre estes. Inclusive, uma das desvantagens na elaboração da Matriz SWOT é a subjetividade envolvida em opiniões como satisfação, sentimentos e preferências individuais (DATTA 2018), por conta disso, ao longo dos anos, aperfeiçoamentos e outros recursos, especialmente quantitativos foram agregados nesta.

\section{Agregando Números na Matriz SWOT}

Uma das limitações da Matriz SWOT é sua incapacidade de determinar quantitativamente o peso e importância dos fatores identificados (MASOZERA et al. 2006; YÜKSEL; DAĞDEVIREN 2007; AKBULAK; CENGIZ, 2014), desta forma, o uso de ferramentas complementares, métodos multicritérios como o AHP (Analytic Hierarchy Process) ou o QSPM (Quantitative Strategic Planning Matrix) são algumas das formas de agregar uma análise quantitativa à Matriz e que vem sendo empregados nos estudos científicos. Por mais que a Matriz SWOT represente um instrumento qualitativo, esta pode ser quantificada por meio de métodos analíticos multicritério (DEMIR; ESBAH; AKGÜN. 2016) agregando confiabilidade e maior precisão ao método. Para Zorlu e Yilmaz, (2020), o uso de métodos multicritérios juntamente com o estabelecimento da Matriz SWOT é uma forma aumentar a precisão da tomada de decisão dentro de processos de planejamento estratégico em ecoturismo, especialmente elencando pesos para os aspectos identificados.

Como destacam Ghorbani et al. (2015) e Arsić, Nikolić e Živković (2017), o uso de análises quantitativas no desenvolvimento da Matriz SWOT, colabora para a determinação das prioridades e dos fatores que possuem maior peso dentre aqueles elencados na matriz, proporcionando maior objetividade dentro do processo de 
formação de estratégias, tendo em vista que, muitas das vezes a Matriz é produzida apenas para elencar aspectos, sem estabelecer critérios claros para a ação, o que pode converter a Matriz numa ferramenta inerte.

O uso de coeficientes, atribuição de pesos e uma escala de pontuação, por exemplo, são algumas das formas de se atribuir valores aos aspectos identificados pela Matriz SWOT, de modo a estabelecer elementos prioritários para planos e ações. A priorização auxilia no estabelecimento de um ranking de prioridades dentro do processo de planejamento, o que é muito positivo para a etapa de desenvolvimento de estratégias. Dentre os estudos analisados, 22 deles adotaram algum recurso quantitativo para mensurar e priorizar os aspectos apontados na Matriz (Quadro 3).

Quadro 3: Estudos Utilizando Recursos Quantitativos na Matriz SWOT.

Frame 3: Studies Using Quantitative Resources in the SWOT Matrix.

\begin{tabular}{|c|c|c|c|}
\hline Autor (es) & País & Objeto de Estudo & Recurso Utilizado \\
\hline $\begin{array}{l}\text { Akbulak e Cengiz } \\
\text { (2014) }\end{array}$ & Turquia & Parque Natural Histórico de Troia & Método AHP \\
\hline $\begin{array}{l}\text { Anggoro et al. } \\
(2019)\end{array}$ & Indonésia & Águas marinhas de Bontang & QSPM, EFE e IFE \\
\hline $\begin{array}{l}\text { Arintoko et al. } \\
(2015)\end{array}$ & Indonésia & Área de turismo Borobudur & Survey \\
\hline Arsić et al. (2018) & Sérvia & Parque Nacional Djerdap & $\begin{array}{l}\text { Analytical Network Process } \\
(A N P) ;\end{array}$ \\
\hline $\begin{array}{l}\text { Arsić, Nikolić e } \\
\text { Živković (2017) }\end{array}$ & Sérvia & Parque Nacional Djerdap & $\begin{array}{l}\text { Analytical Network Process } \\
\text { (ANP); Fuzzy Analytical } \\
\text { Network Process (FANP) }\end{array}$ \\
\hline $\begin{array}{l}\text { Asadpourian, } \\
\text { Rahimian e } \\
\text { Gholamrezai (2020) }\end{array}$ & Irã & Província de Lorestan & Método $A H P$ \\
\hline Celik (2018) & Turquia & Parque Natural de Balamga & Método AHP \\
\hline Ching et al. (2020) & Malásia & Planalto de Cameron & IFE e IFE \\
\hline Datta (2020) & Índia & Mama Bhagne Pahar & Método $A H P$ \\
\hline $\begin{array}{l}\text { Demir e Atanur } \\
\text { (2019) }\end{array}$ & Turquia & Cidade de Iznik & Método $A H P$ \\
\hline $\begin{array}{l}\text { Demir, Esbah e } \\
\text { Akgün (2013) }\end{array}$ & Turquia & Cidade de Igneada & Método $A H P$ \\
\hline $\begin{array}{l}\text { Ghorbani et al. } \\
\text { (2015) }\end{array}$ & Irã & $\begin{array}{l}\text { Pantanal Kaji Namakzar na } \\
\text { Província de South Khorasan }\end{array}$ & QSPM, EFE e IFE \\
\hline Kişi (2019) & Turquia & Cidade de Zonguldak & Método $A H P$ \\
\hline Lestari et al. (2019) & Indonésia & Vila de Pinge - Província de Bali & QSPM, EFE e IFE \\
\hline $\begin{array}{l}\text { Mallick, Rudra e } \\
\text { Samanta (2020) }\end{array}$ & Índia & Rameswaram, Tamil Nadu & QSPM, EFE e IFE \\
\hline $\begin{array}{l}\text { Mostafavi e Jozi } \\
\text { (2015) }\end{array}$ & Irã & Território iraniano & $\begin{array}{l}\text { QSPM, EFE, IFE e Método } \\
A H P\end{array}$ \\
\hline $\begin{array}{l}\text { Navarro-Martínez } \\
\text { et al. (2020) }\end{array}$ & Cuba & Parque Nacional Caguanes & $\begin{array}{l}\text { Escala de importância e } \\
\text { eficácia ( } 1 \text { a } 5 \text { pontos) }\end{array}$ \\
\hline $\begin{array}{l}\text { Nouri, Arjmandi e } \\
\text { Moshiri (2012) }\end{array}$ & Irã & Região de Darabad & QSPM, EFE e IFE \\
\hline Öztürk (2015) & Turquia & $\begin{array}{l}\text { Área de Proteção Natural de } \\
\text { Sarikum }\end{array}$ & Análise de Ranking \\
\hline Öztürk et al. (2013) & Turquia & Bacia Hidrográfica & Análise de Ranking \\
\hline $\begin{array}{l}\text { Ristić, Vukoičić e } \\
\text { Milinčić (2019) }\end{array}$ & Sérvia & Parque Nacional Kopaonik & $\begin{array}{l}\text { Sustainable Rural } \\
\text { Development Index (SRDI) }\end{array}$ \\
\hline $\begin{array}{l}\text { Zorlu e Yilmaz } \\
\text { (2020) }\end{array}$ & Turquia & $\begin{array}{l}\text { Zona de Proteção Ambiental de } \\
\text { Aksaray }\end{array}$ & Método $A H P$ \\
\hline
\end{tabular}

Fonte: Dados da Pesquisa (2020).

Source: Research Data (2020). 
O método QSPM é um método complementar para avaliar com precisão as melhores estratégias dentre as alternativas identificadas, aplicando informações de entrada, tanto externos quanto internos identificados na Matriz (DAVID, 1986). O QSPM é um método que permite decidir entre alternativas dentro do processo de formulação da estratégia (NOURI; ARJMANDI; MOSHIRI, 2012). Utilizar matrizes quantitativas como a QSPM, no desenvolvimento da Matriz SWOT fornece um método analítico para comparar ações entre alternativas viáveis (MALLICK; RUDRA; SAMANTA, 2020).

Um outro recurso utilizado em alguns estudos (ANGGORO et al., 2019; HARIANTO et al., 2020) e associado ao QSPM para estimar valores entre os aspectos indicados na Matriz SWOT é a tabulação dos fatores na Matriz IFE (Internal Factor Evaluation) ou matriz de estimativa de fator interno e na Matriz EFE (External Factor Evaluation) ou matriz de estimativa de fator externo. Os fatores são avaliados por meio de um painel, onde as partes interessadas atribuem uma pontuação (ANGGORO et al., 2019). Neste processo os fatores recebem pontuações, pesos e são interpretados de acordo com os critérios estabelecidos (GHORBANI et al., 2015).

O método $A H P$ é um outro método de tomada de decisão multicritério utilizado para a Matriz SWOT (DEMIR; ESBAH; AKGÜN, 2016; DEMIR; ATANUR, 2019). Este método permite avaliar quantitativamente critérios qualitativos com certa simplicidade, elasticidade e eficiência na avaliação dos resultados (CORREIA et al., 2011). Por meio deste método, é possível tomar decisões com base no estabelecimento de prioridades, o que é fundamental para o alcance de objetivos dentro do processo de planejamento (HALL et al., 2014). O AHP permite que os tomadores de decisão atribuam prioridades para cada fator por meio da comparação de pares e auxilia no desenvolvimento de uma Matriz mais analítica (SHRESTHA; ALAVALAPATI; KALMBACHER, 2004; LESKINEN et al., 2006).

O Método AHP pode ser utilizado na Matriz SWOT para classificar os componentes e os critérios, analisando assim estes de acordo com sua importância e, portanto, permitindo a quantificação e a leitura de critérios de forma específica (AKGÜN et al., 2012). Deste modo, o AHP permite converter dados verbais e subjetivos em algo numérico e dados para avaliação quantitativa (DEMIR; ESBAH; AKGÜN, 2016).

Segundo Saaty (1987) o método AHP permite a avaliação de variáveis qualitativas e quantitativas em conjunto. $O$ uso do $A H P$ é baseado no estabelecimento de uma hierarquia, que permite analisar múltiplos critérios (SAATY. 1980). Após a formulação da Matriz SWOT, é importante estabelecer critérios para determinar a decisão ideal, o que justifica o uso de outras ferramentas, como $A H P$, um método de comparação de pares que prioriza fatores usando escala de importância de nove pontos (Quadro 4), como sugerido inicialmente por Saaty (1980). 
Quadro 4: Escala de Importância Relativa.

Frame 4: Relative Importance Scale.

\begin{tabular}{|c|l|l|}
\hline $\begin{array}{c}\text { Intensidade de } \\
\text { Importância }\end{array}$ & \multicolumn{1}{|c|}{ Definição } & \multicolumn{1}{c|}{ Explanação } \\
\hline $\mathbf{1}$ & Importância igual & $\begin{array}{l}\text { Dois fatores contribuem igualmente para o } \\
\text { objetivo. }\end{array}$ \\
\hline $\mathbf{3}$ & $\begin{array}{l}\text { Pouca importância de um sobre } \\
\text { o outro }\end{array}$ & $\begin{array}{l}\text { A experiência e o julgamento favorecem } \\
\text { ligeiramente um ao outro. }\end{array}$ \\
\hline $\mathbf{5}$ & Importância essencial ou forte & $\begin{array}{l}\text { A experiência e o julgamento favorecem } \\
\text { fortemente um em relação ao outro. }\end{array}$ \\
\hline $\mathbf{7}$ & $\begin{array}{l}\text { Importância muito forte ou } \\
\text { demonstrada }\end{array}$ & $\begin{array}{l}\text { Experiência e julgamento favorecem } \\
\text { fortemente um sobre o outro. }\end{array}$ \\
\hline $\mathbf{9}$ & Importância absoluta & $\begin{array}{l}\text { A evidência que favorece um em relação ao } \\
\text { outro é a mais alta possível validade. } \\
\text { Quando o compromisso é necessário. }\end{array}$ \\
\hline $\mathbf{2 , 4 , 6 , 8}$ & Valores intermediários & \\
\hline
\end{tabular}

Fonte: Saaty (1980).

Source: Saaty (1980).

O desenvolvimento da Matriz SWOT em conjunto com AHP, permite que a Matriz atinja uma visão mais analítica, pois os fatores SWOT qualitativos são quantificados, baseado em sua significância (KAJANUS et al., 2004). O método $A^{\prime} W O T$ (abreviação de $A H P+S W O T$ ), apresenta uma perspectiva integrada e ajuda na concepção de um processo de planejamento estratégico, fortalecendo o lado quantitativo deste (KIŞI, 2019). Dentro do método híbrido da $A^{\prime} W O T$, os passos básicos são: desenvolver a Matriz SWOT; comparar pares entres fatores SWOT usando o AHP; comparar pares entre os quatro quadrantes da SWOT usando AHP e, por fim, formular estratégias e processos avaliativos (KURTTILA et al., 2000).

Posterior ao método AHP foi desenvolvido o método ANP (Analytic Network Process) que representa uma forma mais generalizada do método AHP e foi também desenvolvido por Saaty em 1996 (ARSIĆ et al., 2018). De forma geral, o método consiste em duas partes: na primeira há uma hierarquia controlada ou rede de critérios e subcritérios e na segunda parte é estabelecida a influência entre os elementos e agrupamentos (ARSIĆ et al., 2018).

Como forma de melhorar a qualidade da aplicação da Matriz SWOT, a quantificação dos fatores formadores de uma Matriz tem se expandido, como uma maneira de tomada de decisão em condições de incerteza (KHEIRKHAH et al., 2014). Por conta da falta de termos de mediação e avaliação, a Matriz, embora permita o diagnóstico dos fatores que determinam o estado atual de um objeto em avaliação, acaba perdendo eficácia, por isso a necessidade de se agregar análises quantitativas em conjunto com a Matriz SWOT.

\section{A Matriz TOWS para o Desenvolvimento da Estratégia}

A Matriz SWOT não deve ser vista apenas como um agrupamento de pontos fortes e fracos, ameaças e oportunidades, por isso, são necessários desdobramentos posteriores a construção da Matriz (HELMS; NIXON, 2010). Como tratado anteriormente, o desenvolvimento da Matriz envolve uma série de etapas, instrumentos e abordagens, que podem ser apenas qualitativas, mas que ganham maior relevância quando associadas a métodos quantitativos. 
Como pontua Koch (2000 apud CHERMACK; KASSHANNA, 2007), há muitos equívocos e conceitos errôneos sobre a Matriz SWOT, tais como acreditar que a SWOT tem uma capacidade analítica própria, sendo que na verdade esta é apenas uma estrutura analítica. A Matriz deve ser direcionada para a formulação de estratégia buscando minimizar ameaças e fraquezas e maximizar pontos fortes e oportunidades, para ser considerada uma boa estratégia (RAUCH, 2007).

Para além da identificação dos fatores que compõem a Matriz SWOT, alguns estudos também apontam para as estratégias que podem ser adotadas, a partir dos fatores identificados (TEHRANCHI; SHAFIEI; SHAGHAGHI, 2013; ÖZTÜRK, 2015; SUGITO et al., 2019; ANGGORO et al., 2019; HARIANTO et al., 2020; ZORLU; YILMAZ, 2020). É salutar a relevância de se estabelecer as estratégias, logo após a determinação da Matriz para que esta não se torne ineficaz, tendo em vista que, isoladamente a ferramenta apenas apresenta um diagnóstico, sendo apenas um passo inicial para a posterior formulação de ações, planos, estratégias etc.

A Matriz TOWS constitui outra importante contribuição para a Matriz SWOT dada por Weihrich (1982). Este autor propôs a Matriz (Quadro 5), como uma etapa posterior ao desenvolvimento da Matriz SWOT. A TOWS ajuda a descobrir os relacionamentos sistemáticos que existem entre forças, fraquezas, oportunidades e ameaças, oferecendo desta forma uma estrutura para gerar estratégias com base nestas relações (WEIHRICH, 1982). De acordo com Weihrich (1982), a Matriz TOWS geralmente é empregada para auxiliar a análise de informações no processo de sistematização de escolhas estratégicas, isto é, aquelas que serão priorizadas.

Quadro 5: Matriz TOWS para o Desenvolvimento de Alternativas Estratégicas

Frame 5: TOWS Matrix for Developing Strategic Alternatives

\begin{tabular}{|l|l|lr|}
\hline & Forças internas (S) & Fraquezas internas (W) \\
\hline $\begin{array}{l}\text { Oportunidades } \\
\text { externas (O) }\end{array}$ & $\begin{array}{l}\text { SO: Estratégias "Maxi-Maxi" - } \\
\text { Estratégias que usam como pontos } \\
\text { fortes para maximizar oportunidades. }\end{array}$ & $\begin{array}{l}\text { WO: Estratégias "Mini-Maxi" } \\
\text { Estratégias que minimizam } \\
\text { fraquezas as } \\
\text { oportunidades. }\end{array}$ & $\begin{array}{l}\text { aproveitando } \\
\text { as }\end{array}$ \\
\hline $\begin{array}{l}\text { Ameaças } \\
\text { externas (T) }\end{array}$ & $\begin{array}{l}\text { ST: Estratégias "Maxi-Mini" - } \\
\text { Estratégias que usam pontos fortes } \\
\text { para minimizar ameaças. }\end{array}$ & $\begin{array}{l}\text { WT: Estratégias "Mini-Mini" } \\
\text { Estratégias que minimizam a fraqueza } \\
\text { e evitar ameaças. }\end{array}$ \\
\hline
\end{tabular}

Fonte: Weihrich (1982).

Source: Weihrich (1982).

Na Matriz TOWS os elementos da Matriz SWOT são combinados (Quadro 5 ), assim tem-se as seguintes combinações: $S O$ (forças-oportunidades) é a estratégia onde os pontos fortes são usados para maximizar oportunidades, isso implica que as condições são favoráveis; WO (fraquezas-oportunidades), onde fraquezas são minimizadas para tirar vantagens de oportunidades; $S T$ (forçasameaças) em que forças são usadas para minimizar ameaças e; WT (fraquezasameaças), uma forte relação entre fraquezas e ameaças indicam uma condição alarmante e uma necessidade de defesa estratégias (CHING et al., 2020; DATTA, 2020).

A TOWS colabora com a SWOT no sentido de desenvolver estratégias maximizando os pontos fortes e oportunidades, minimizando as fraquezas identificadas (ASADPOURIAN; RAHIMIAN; GHOLAMREZAI, 2020) sendo que esta vem sendo utilizada por diversos estudos no contexto do planejamento de 
atividades, ações e projetos de ecoturismo, tais como nos estudos de Arsíc et al. (2017), Ching et al. (2020), Datta (2020), entre outros.

De maneira geral, analisando o processo posterior ao desenvolvimento da Matriz SWOT, a formulação de estratégias e ações dão continuidade aos aspectos identificados na Matriz, assim, alguns passos interessantes para o desenvolvimento de matrizes para fins de planejamento de atividades envolvendo o ecoturismo, seriam: 1) Identificação das direções (formulação de uma visão e estabelecimento de objetivos em projetos de ecoturismo); 2) Análise estratégica (análise do ambiente - neste ponto, a Matriz SWOT pode ser uma protagonista para se analisar atividades recreativas); 3) Análise das opções estratégicas (avaliação das alternativas, determinação de critérios de seleção, etc.) Neste ponto, a Matriz TOWS e a adoção de métodos quantitativos para determinar as prioridades, pode ser úteis; 4) Seleção da estratégia e; 5) Implementação da estratégia, desenvolvimento de planos de ação, determinação de sistemas de avaliação e monitoramento de indicadores.

\section{Considerações Finais}

A partir da análise empreendida, conclui-se que a Matriz SWOT é utilizada para diferentes objetos e em diferentes escalas dentro do ecoturismo. Assim, é possível utilizar a ferramenta, desde o planejamento de uma atividade vinculada ao ecoturismo, como a observação de pássaros, até o planejamento de diversas atividades a serem desenvolvidas em um espaço de conservação, como um parque.

A Matriz se propõe a auxiliar no processo de desenvolvimento da estratégia, sendo seu uso aplicado para a formulação de estratégias e ações. Neste sentido, deve ser entendida como um apoio ao processo de gestão, no sentido de compreender o cenário onde o objeto se encontra e como atuar neste. Utilizando a Matriz SWOT os planejadores têm em mãos uma ferramenta eficaz para analisar o seu ambiente.

Há na gestão e no planejamento em ecoturismo um bom espaço para a utilização da Matriz SWOT como um instrumento de suporte ao processo de tomada de decisão. Seja apenas por meio do desenvolvimento de uma Matriz de forma qualitativa ou agregando análises quantitativas a esta, a ferramenta se mostra propensa a auxiliar os tomadores de decisões a determinar os principais elementos a serem focados dentro de uma estratégia.

O presente estudo forneceu uma descrição da ferramenta e de seu uso aplicado ao ecoturismo. Para isso, foram analisados alguns estudos que utilizaram a Matriz SWOT em diferentes contextos. Neste sentido, observamos que, a Matriz é uma ferramenta que tem sido incorporada no contexto do ecoturismo nos últimos anos, especialmente em países asiáticos.

Foi notado que, a Matriz SWOT vem sendo utilizada com bons resultados, mas com uma série de limitações do ponto de vista da sua elaboração. Como visto, muitos estudos não deixam claro o seu processo de produção, seja não indicando as fontes de dados ou utilizando fontes de dados restritas e ainda, utilizando instrumentos que limitam o desenvolvimento da ferramenta. Apesar das restrições qualitativas da Matriz, foi observado que esta limitação pode ser superada pelo uso paralelo de outros métodos auxiliares ao desenvolvimento da Matriz SWOT, especialmente métodos quantitativos, que buscam estabelecer prioridades dentro dos fatores apontados pela SWOT. 
Ao desenvolver a análise dos artigos que se utilizam da Matriz SWOT, foi notado que faltam pesquisas destinadas aos benefícios e ganhos identificados pelo uso da ferramenta. Outro tipo de estudo que seria de grande relevância, são aqueles destinados a avaliar se os aspectos apontados na Matriz SWOT foram realmente relevantes dentro do processo desenvolvido, visto que os artigos não apresentam se de fato, os aspectos apontados nas Matrizes foram desenvolvidos posteriormente. Não há também estudos identificando as barreiras e obstáculos que possam interferir no processo de elaboração da Matriz SWOT.

As pesquisas destinadas a identificar os resultados na melhoria da gestão/planejamento por meio do uso da SWOT e como que os participantes percebem os benefícios do uso da SWOT dentro do processo de tomada de decisão, seriam de grande valia para o desenvolvimento desta ferramenta no contexto do ecoturismo.

\section{Referências}

AÇIKSÖZ, S. et al. Linkages among ecotourism, landscape and natural resource management, and livelihood diversification in the region of Suğla Lake, Turkey. International Journal of Sustainable Development \& World Ecology, v. 23, n. 1, p. 15-27, 2016.

AKBULAK, C.; CENGIZ, T. Determining ecotourism strategies using A'WOT hybrid method: case study of Troia Historical National Park, Çanakkale, Turkey. International Journal of Sustainable Development \& World Ecology, v. 21, n. 4, p. 380-388, 2014.

AKGÜN, A.A.; VAN LEEUWEN, E.; NIJKAMP, P. A multi-actor multi-criteria scenario analysis of regional sustainable resource policy. Ecological Economics, v. 78, p. 19-28, 2012.

AKHTER, S. H. Strategic planning, hypercompetition, and knowledge management. Business Horizons, v. 46, n. 1, p. 19-24, jan./fev. 2003.

ALMEIDA, A.C.L.; CARDOSO, A.J.G. Diagnóstico rápido participativo e Matriz SWOT: estratégias de planejamento estratégico com base na atual posição do curso de Secretariado executivo UEPA. Revista de Gestão e Secretariado, v. 5, n. 2, p. 117-137, 2014.

ANGGORO, S. et al. Strategies for sustainable ecotourism development in the marine waters of Bontang City, Indonesia. Aquaculture, Aquarium, Conservation \& Legislation, v. 12, n. 5, p. 1779-1787, 2019.

ANUP, K. C. Ecotourism and its role in sustainable development of Nepal. INTECH Open Science, p. 31-59, 2016.

ARÉVALO, P. et al. La ruta turística enológica en Querétaro y Baja California, México: Un enfoque estratégico. Revista interamericana de ambiente y turismo, $\mathrm{v}$. 14, n. 2, p. 122-134, 2018.

ARINTOKO, A. et al. Community-based tourism village development strategies: a case of Borobudur tourism village area, Indonesia. GeoJournal of Tourism and Geosites, v. 29, n. 2, p. 398-413, 2020. 
ARKSEY, H.; O'MALLEY, L. Scoping studies: towards a methodological framework. International journal of social research methodology, v. 8, n. 1, p. 1932, 2005.

ARSIĆ, S. et al. A new approach within ANP-SWOT framework for prioritization of ecosystem management and case study of National Park Djerdap, Serbia. Ecological Economics, v. 146, p. 85-95, 2018.

ASADPOURIAN, Z.; RAHIMIAN, M.; GHOLAMREZAI, S. SWOT-AHP-TOWS Analysis for Sustainable Ecotourism Development in the Best Area in Lorestan Province, Iran. Social Indicators Research, v. 152, n. 1, p. 289-315, 2020.

AVILA, M.A. et al. El Método Dep Como Herramienta Para El Análisis De Destinos Turísticos. Su aplicación en llhéus/BA-Brasil. Estudios y perspectivas en turismo, v. 24, n. 2, p. 414-429, 2015.

AZEVEDO, M.C.; COSTA, H.G. Métodos para avaliação da postura estratégica. REGE Revista de Gestão, v. 8, n. 2, 2010.

BARNEY, J.B.; HESTERLY, W. S. Administração estratégica e vantagem competitiva: conceitos e casos (3a e.). São Paulo: Pearson, 2011.

BRASIL. Programa de Regionalização do Turismo - Roteiros do Brasil: Turismo e Sustentabilidade. Secretaria Nacional de Políticas de Turismo. Departamento de Estruturação, Articulação e Ordenamento Turístico. Coordenação Geral de Regionalização - Brasília: Ministério do Turismo, 2007.

CELIK, D. Determination of the most suitable ecotourism activities with the analytic hierarchy process: A case study of Balamba Natural Park, Turkey. Applied Ecology and Environmental Research, v. 16, n. 4, p. 4329-4355, 2018.

CHARNOV, H.B.; MONTANA, J.P. Administração. São Paulo: Saraiva, 1998.

CHERMACK, T.J.; KASSHANNA, B.K. The use and misuse of SWOT analysis and implications for HRD professionals. Human Resource Development International, v. 10, n. 4, p. 383-399, 2007.

CHING, S.L. et al. Sustainable ecotourism development strategies through strengths, weaknesses, opportunities, and threats analysis: The case of Cameron Highlands, Malaysia. Business Strategy \& Development. p. 1-7, 2020.

COHEN, M.; SILVA, J.F. Evaluation of collaborative strategies for ecotourism and recreational activities in natural parks of Rio de Janeiro. Revista de Administração Pública, v. 44, n. 5, p. 1097-1123, 2010.

COLLINS-KREINER, N.; WALL, G. Evaluating tourism potential: A SWOT analysis of the Western Negev, Israel. Turizam: međunarodni znanstveno-stručni časopis, v. 55, n. 1, p. 51-63, 2007.

CORREIA, A.; KOZAK, M.; FERRADEIRA, J. Impact of culture on tourist decision-making styles. International Journal of Tourism Research, v. 13, n. 5, p. 433-446, 2011.

COSTA, C.C.; GOMES, L.J. Parque Nacional Sierra de Itabaiana-Brasil: Una herramienta para el ecoturismo. Estudios y perspectivas en turismo, v. 23, n. 1, p. 190-206, 2014.

CREST. Market analysis of bird-based tourism. Washington, DC: Center for Responsible Tourism, 2015. 
DATTA, K. Geo-environmental analysis and management of Pagla river basin, part of Jharkhand and West Bengal with special reference to water logging: a study in applied geomorphology, Ph. D. Thesis, Visva-Bharati. 2018.

DATTA, K. Application of SWOT-TOWS Matrix and Analytical Hierarchy Process (AHP) in the Formulation of Geoconservation and Geotourism Development Strategies for Mama Bhagne Pahar: an Important Geomorphosite in West Bengal, India. Geoheritage, v. 12, n.45, 2020.

DAUDT, H.M.L.; VAN MOSSEL, C.; SCOTT, S.J. Enhancing the scoping study methodology: a large, inter-professional team's experience with Arksey and O'Malley's framework. BMC Medical Research Methodology, v. 13, n. 1, p. 48, 2013.

DAVID, F. Strategic Management, 6th ed. New Jersey, Prentice Hall, 1997.

DAVID, F.R. The strategic planning matrix-a quantitative approach. Long Range Planning, v. 19, n. 5, p. 102-107, 1986.

DEMIR, S.; ATANUR, G. The prioritization of natural-historical based ecotourism strategies with multiple-criteria decision analysis in ancient UNESCO city: Iznik-Bursa case. International Journal of Sustainable Development \& World Ecology, v. 26, n. 4, p. 329-343, 2019.

DEMIR, S.; ESBAH, H.; AKGÜN, A.A. Quantitative SWOT analysis for prioritizing ecotourism-planning decisions in protected areas: Igneada case. International Journal of Sustainable Development \& World Ecology, v. 23, n. 5, p. 456-468, 2016.

FERREIRA, E.P. et al. Gestão estratégica em frigoríficos: aplicação da análise SWOT na etapa de armazenagem e expedição. Gestão \& Produção, v. 26, n. 2, 2019.

GARCíA REINOSO, N.; CHILAN, D.; YAMIL, N. El producto turístico comunitario como estrategia para diversificar las economías locales del cantón Bolívar, provincia de Manabí, Ecuador. Revista interamericana de ambiente y turismo, v. 13, n. 1, p. 105-116, 2017.

GARCÍA, N.; QUINTERO, Y. Producto de sol y playa para el desarrollo turístico del Municipio Trinidad de Cuba. Revista interamericana de ambiente y turismo, v. 14, n. 1, p. 52-64, 2018.

GHORBANI, A. et al. Ecotourism sustainable development strategies using SWOT and QSPM model: A case study of Kaji Namakzar Wetland, South Khorasan Province, Iran. Tourism Management Perspectives, v. 16, p. 290-297, 2015.

GORANCZEWSKI, B.; PUCIATO, D. SWOT analysis in the formulation of tourism development strategies for destinations. Turyzm, v. 20, n. 2, p. 45-53, 2010.

HALL, A.; DAY, M. Ecotourism In The State Forest Karst Of Puerto Rico. Journal of Cave \& Karst Studies, v. 76, n. 1, 2014.

HARIANTO, S.P. et al. Development strategy for ecotourism management based on feasibility analysis of tourist attraction objects and perception of visitors and local communities. Biodiversitas Journal of Biological Diversity, v. 21, n. 2, p. 689-698, 2020. 
HELMS, M.M.; NIXON, J. Exploring SWOT analysis-where are we now? Journal of Strategy and Management, 2010.

IBRET, B.U.; AYDINOZU, D.; BASTEMUR, C. A geographic study on the effects of coastal tourism on sustainable development: coastal tourism in Cide. International Journal of Sustainable Development \& World Ecology, v. 20, n. 2, p. 134-141, 2013.

INTERNATIONAL YEAR OF ECOTOURISM. (IYE). WTO-UNEP international year of ecotourism. Concept $2018 . \quad$ Paper. Disponível em: $<$ http://www.worldtourism.org/sustainable/wto-unep-conceptpaper.htm>. Acesso em: 14 jan. 2021.

KAJANUS, M.; KANGAS, J.; KURTTILA, M. The use of value focused thinking and the A'WOT hybrid method in tourism management. Tourism Management, v. 25, n. 4, p. 499-506, 2004.

KANGAS, J.J. et al. Incorporating MCDS and voting into SWOT-basic idea and experiences. Serbian Journal of Management, v. 11, n. 1, p. 1-13, 2016.

KHEIRKHAH, A.; BABAEIANPOUR, M.; BASSIRI, P. Development of a hybrid method based on fuzzy PROMETHEE and ANP in the framework of SWOT analysis for strategic decisions. International Research Journal of Applied and Basic Sciences, v. 8, n. 4, p. 504-515, 2014.

KIŞI, N. A strategic approach to sustainable tourism development using the A'WOT hybrid method: A case study of Zonguldak, Turkey. Sustainability, v. 11, n. 4, p. 964, 2019.

$\mathrm{KOCH}$, A.J. SWOT does not need to be recalled: It needs to be enhanced. Swinburne University of Technology, 2000.

KRONENBERG, J. Birdwatchers' wonderland? Prospects for the development of birdwatching tourism in Poland. Journal of Ecotourism, v. 15, n. 1, p. 78-94, 2016.

KURTTILA, M. et al. Utilizing the analytic hierarchy process (AHP) in SWOT analysis-a hybrid method and its application to a forest-certification case. Forest Policy and Economics, v. 1, n. 1, p. 41-52, 2000.

LESKINEN, L.A. et al. Adapting modern strategic decision support tools in the participatory strategy process - a case study of a forest research station. Forest Policy and Economics, v. 8, n. 3, p. 267-278, 2006.

LESTARI, N.P.N.E. et al. The role of subak as culture capital to develop community based tourism village (case study in Pinge Village, Bali Province, Indonesia). Scientific Papers Series-Management, Economic Engineering in Agriculture and Rural Development, v. 19, n. 3, p. 357-367, 2019.

LEVAC, D.; COLQUHOUN, H.; O'BRIEN, K.K. Scoping studies: advancing the methodology. Implementation Science, v. 5, n. 1, p. 69, 2010.

LÓPEZ SANTILLÁN, A.A.; GUARDADO, G.M. Ecoturismo, desarrollo y sustentabilidad: un recorrido por senderos interpretativos de poder, mercado y simulacro. In: GUERRERO, A.C.; MACHUCA, J.A. (coords.), Turismo y antropología: miradas del Sur y el Norte, Universidad Autónoma Metropolitana-Juan Pablos Editor, México D. F, pp. 201-232, 2012. 
LY, T.P.; XIAO, H. The choice of a park management model: A case study of Phong Nha-Ke Bang National Park in Vietnam. Tourism Management Perspectives, v. 17, p. 1-15, 2016.

MALLICK, S.K.; RUDRA, S.; SAMANTA, R. Sustainable ecotourism development using SWOT and QSPM approach: A study on Rameswaram, Tamil Nadu. International Journal of Geoheritage and Parks, 2020.

MARANHÃO, C.H.S.; AZEVEDO, F.F. A Representatividade do Ecoturismo para a gestão pública do turismo no Brasil: uma análise do Plano Nacional de Turismo 2018-2022. Revista Brasileira de Ecoturismo, São Paulo, v. 12, n. 1, p. 09-35, 2019.

MASOZERA, M.K. et al. Assessing the suitability of community-based management for the Nyungwe Forest Reserve, Rwanda. Forest Policy and Economics, v. 8, n. 2, p. 206-216, 2006.

MESTANZA-RAMÓN, C. et al. Tourism in Continental Ecuador and the Galapagos Islands: An Integrated Coastal Zone Management (ICZM) Perspective. Water, v. 12, n. 6 , p. $1647,2020$.

MEZA-ARCE, M.I. et al. Unraveling the white shark observation tourism at Guadalupe Island, Mexico: Actors, needs and sustainability. Marine Policy, v. 119, p. $104056,2020$.

MINTZBERG, H.; AHLSTRAND, B.; LAMPEL, J. Safári da estratégia. Bookman Editora, 2009.

MONDAL, M.; HAQUE, S. SWOT analysis and strategies to develop sustainable tourism in Bangladesh. UTMS Journal of Economics, v. 8, n. 2, p. 159-167, 2017.

MORALES-FERNÁNDEZ, E.J.; LANQUAR, R. El futuro turístico de una ciudad Patrimonio de la Humanidad: Córdoba 2031. Tourism \& Management Studies, v. 10, n. 2, p. 07-16, 2014.

MOSTAFAVI, S.S.; JOZI, S.A. An Environmental Management Plan for Iran's Accession to the World Trade Organization. Polish Journal of Environmental Studies, v. 24, n. 2, 2015.

MUGO, M. et al. Using Tows Matrix as a Strategic Decision-Making Tool in Managing KWS Product Portfolio. African Multidisciplinary Journal of Research, v. 2, n. 1, 2017.

MUSTIKA, A.; ADITYA, M.K. SWOT analysis of rural tourism development: case study of Kampung Tajur, Purwakarta. In: 2nd International Conference on Tourism, Gastronomy, and Tourist Destination (ICTGTD 2018). Atlantis Press, 2018.

NAVARRO-MARTÍNEZ, Z.M. et al. Using SWOT analysis to support biodiversity and sustainable tourism in Caguanes National Park, Cuba. Ocean \& Coastal Management, v. 193, p. 105188, 2020.

NEGA, D. Management Issues and the Values of Safeguarding the Intangible Cultural Heritage for Cultural Tourism Development: The Case of Ashendye Festival, Lalibela, Ethiopia. Management, v. 38, 2018. 
NOURI, J.; ARJMANDI, R.; MOSHIRI, S. P. Strategic management for sustainable ecotourism in darabad region in Tehran, Iran. Asian Journal of Chemistry, v. 24, n. 5, p. 2265, 2012.

NUNES, E.R.; MARTINS, M.F. Indicadores de sustentabilidade para o turismo sustentável: um estudo no município de Bananeiras (PB). Revista Brasileira de Ecoturismo, v. 12, n. 2, 2019.

OKAN, T. et al. Assessing ecotourism potential of traditional wooden architecture in rural areas: The case of Papart Valley. Sustainability, v. 8, n. 10, p. 974, 2016.

ÖZTÜRK, S. Determining management strategies for the Sarikum nature protection area. Environmental Monitoring and Assessment, v. 187, n. 3, p. 113, 2015.

ÖZTÜRK, S. et al. Stakeholder participation as a means for river basin management plan. Journal of Environmental Protection and Ecology, v. 14, n. 3, p. 1097-1106, 2013.

PETERS, M.D.J. et al. Guidance for conducting systematic scoping reviews. International Journal of Evidence-Based Healthcare, v. 13, n. 3, p. 141146, 2015.

PFEIFF, G.K. et al. Turismo y Desarrollo Local Sustentable: Factores limitantes y potencialidades de la playa de Ajuruteua en el Estado de Pará, Brasil. Estudios y perspectivas en turismo, v. 27, n. 3, p. 716-736, 2018.

PIRSELIMOĞLU, Z.; DEMIREL, Ö. A study of an ecologically based recreation and tourism planning approach: a case study on Trabzon Çalköy high plateau in Turkey. International Journal of Sustainable Development \& World Ecology, v. 19, n. 4, p. 349-360, 2012.

PORTER, M.E. Towards a dynamic theory of strategy. Strategic Management Journal, v. 12, n. S2, p. 95-117, 1991.

RANDLE, E.J.; HOYE, R. Stakeholder perception of regulating commercial tourism in Victorian National Parks, Australia. Tourism Management, v. 54, p. 138-149, 2016.

RANGEL, L.A.; SINAY, L. Ecoturismo como ferramenta para criação de Unidades de Conservação no estado do Rio de Janeiro. Revista Brasileira de Ecoturismo, v. 12, n. 4, 2019.

RAUCH, P. SWOT analyses and SWOT strategy formulation for forest owner cooperations in Austria. European Journal of Forest Research, v. 126, n. 3, p. 413420, 2007.

REIHANIAN, A. et al. Sustainable tourism development strategy by SWOT analysis: Boujagh National Park, Iran. Tourism Management Perspectives, v. 4, p. 223-228, 2012.

RISTIĆ, D.; VUKOIČIĆ, D.; MILINČIĆ, M. Tourism and sustainable development of rural settlements in protected areas-Example NP Kopaonik (Serbia). Land Use Policy, v. 89, p. 104231, 2019.

SAATY, R.W. The analytic hierarchy process-what it is and how it is used. Mathematical modelling, v. 9, n. 3-5, p. 161-176, 1987.

SAATY, T.L..; ÖZDEMIR, M.S. How many judges should there be in a group? Annals of Data Science, v. 1, n. 3-4, p. 359-368, 2015. 
SAATY, T.L. The analytical hierarchy process. McGraw-Hill, New York. 1980.

SANTOS, B.R.P.; DAMIAN, I.P.M. O mapeamento do conhecimento por meio da análise SWOT: estudo em uma organização pública de saúde. Em Questão, v. 24, n. 3, p. 253-274, 2018.

SCOLOZZI, R. et al. Ecosystem services-based SWOT analysis of protected areas for conservation strategies. Journal of Environmental Management, v. 146, p. 543551, 2014.

SHRESTHA, R.K.; ALAVALAPATI, J.R.R.; KALMBACHER, R.S. Exploring the potential for silvopasture adoption in south-central Florida: an application of SWOTAHP method. Agricultural Systems, v. 81, n. 3, p. 185-199, 2004.

SILVA, T.R.; MEDEIROS, M.V.B.; MEDEIROS, G.R.N. Gestão de Riscos no Framework Scrum Utilizando Análise Swot. Revista de Tecnologia da Informação e Comunicação da Faculdade Estácio do Pará, v. 1, n. 1, p. 48-57, 2018.

SPAOLONSE, E.; MARTINS, S.S.Oliveira. Ecoturismo: uma ponte para o turismo sustentável. Revista Brasileira de Ecoturismo, v. 9, n. 6, 2016.

SUGITO, T. et al. Community empowerment model of coastal border based on ecotourism. Masyarakat, Kebudayaan dan Politik, v. 32, n. 4, p. 363-377, 2019.

SULISTYADI, Y.; EDDYONO, F.; HASIBUAN, B. Model of sustainable tourism development strategy of the Thousand Islands Tourism Area-Jakarta. Journal of Economics, Management and Trade, p. 1-17, 2017.

TEHRANCHI, M.; SHAFIEI, A.D.; SHAGHAGHI, S. Studying solutions of development of tourism in Urmia Lake based on SWOT model. Advances in Environmental Biology, p. 4505-4512, 2013.

TRICCO, A.C. et al. PRISMA extension for scoping reviews (PRISMA-ScR): checklist and explanation. Annals of internal medicine, v. 169, n. 7, p. 467-473, 2018.

URRY, J. O olhar do turista. Studio Nobel, 1996.

VAGIONA, D. et al. The development of sustainable tourism indicators for the islands of the Northern Sporades region in Greece. FEB-FRESENIUS Environmental Bulletin, p. 1301, 2017.

VARGAS DEL RÍO, D.; BRENNER, L. Ecoturismo comunitario y conservación ambiental: la experiencia de La Ventanilla, Oaxaca, México. Estudios sociales, v. 21, n. 41, p. 31-63, 2013.

VLADI, E. Tourism Development Strategies, SWOT analysis and improvement of Albania's image. European Journal of Sustainable Development, v. 3, n. 1, p. 167-178, 2014.

WEIHRICH, H. The TOWS matrix-A tool for situational analysis. Long range planning, v. 15, n. 2, p. 54-66, 1982.

YILMAZ, A.; ZORLU, K. SWOT-AHS Analizi Kullanilarak Sinop'ta Sürdürülebilir Turizm Stratejilerinin Önceliklendirilmesi. Journal of International Social Research, v. 11, n. 61, 2018.

YÜKSEL, İ.; DAGDEVIREN, M. Using the analytic network process (ANP) in a SWOT analysis-A case study for a textile firm. Information Sciences, v. 177, n. 16, p. 3364-3382, 2007. 
ZORLU, K.; YILMAZ, A. Determination of Strategies of Ecotourism in Protected Areas with SWOT-AHP Method: The Case of Aksaray-Ihlara Special Environmental Protection Zone (SEPZ). Coğrafya Dergisi, n. 40, p. 247-257.2020.

Ítalo de Paula Casemiro: Universidade Federal do Rio de Janeiro, Rio de Janeiro, RJ, Brasil.

E-mail: itcasemiro@hotmail.com

Link para o currículo Lattes: http://lattes.cnpq.br/0400215407886003

Bruno Francisco Teixeira Simões: Universidade Federal do Estado do Rio de Janeiro, Rio de Janeiro, RJ, Brasil.

E-mail: bruno.simoes@uniriotec.br

Link para o currículo Lattes: http://lattes.cnpq.br/0985291000032685

Camila Maria dos Santos Moraes: Universidade Federal do Estado do Rio de Janeiro, Rio de Janeiro, RJ, Brasil.

E-mail: camila.moraes@unirio.br

Link para o currículo Lattes: http://lattes.cnpq.br/9283123237866240

Data de submissão: 10 de agosto de 2021

Data de recebimento de correções: 25 de dezembro de 2021

Data do aceite: 25 de dezembro de 2021

Avaliado anonimamente 